\title{
Inferring foliar water uptake using stable isotopes of water
}

\author{
Gregory R. Goldsmith ${ }^{1,2}$ Marco M. Lehmann ${ }^{1,3}$ - Lucas A. Cernusak ${ }^{4}$. \\ Matthias Arend $^{3,5} \cdot$ Rolf T. W. Siegwolf ${ }^{1,3}$
}

Received: 4 April 2017 / Accepted: 11 July 2017 / Published online: 22 July 2017

(c) Springer-Verlag GmbH Germany 2017

\begin{abstract}
A growing number of studies have described the direct absorption of water into leaves, a phenomenon known as foliar water uptake. The resultant increase in the amount of water in the leaf can be important for plant function. Exposing leaves to isotopically enriched or depleted water sources has become a common method for establishing whether or not a plant is capable of carrying out foliar water uptake. However, a careful inspection of our understanding of the fluxes of water isotopes between leaves and the atmosphere under high humidity conditions shows that there can clearly be isotopic exchange between the two pools even in the absence of a change in the mass of water in the leaf. We provide experimental evidence that while leaf water isotope ratios may change following exposure to a fog event using water with a depleted oxygen isotope
\end{abstract}

Communicated by Russell K. Monson.

Electronic supplementary material The online version of this article (doi:10.1007/s00442-017-3917-1) contains supplementary material, which is available to authorized users.

Gregory R. Goldsmith

goldsmit@chapman.edu

1 Laboratory for Atmospheric Chemistry, Ecosystem Fluxes Group, Paul Scherrer Institute, 5232 Villigen, Switzerland

2 Schmid College of Science and Technology, Chapman University, Orange, CA 92866, USA

3 Forest Dynamics, Swiss Federal Research Institute for Forest, Snow and Landscape Research (WSL), 8903 Birmensdorf, Switzerland

4 College of Science and Engineering, James Cook University, Cairns, QLD 4878, Australia

5 Department of Environmental Sciences-Botany, University of Basel, 4051 Basel, Switzerland ratio, leaf mass only changes when leaves are experiencing a water deficit that creates a driving gradient for the uptake of water by the leaf. Studies that rely on stable isotopes of water as a means of studying plant water use, particularly with respect to foliar water uptake, must consider the effects of these isotopic exchange processes.

Keywords Fog · Isotope dendrochronology · Leaf wetting $\cdot$ Plant-water relations $\cdot$ Stomata

Foliar water uptake describes the process by which plants absorb water into their leaves, resulting in a net increase in the mass of water in the leaf. This occurs when saturating atmospheric water vapor conditions result in a driving gradient for water to enter into a leaf that is at a more negative water potential (Simonin et al. 2009; Goldsmith 2013; Vesala et al. 2017). The conditions necessary for this phenomenon are often observed in dew- and fog-affected ecosystems such as coastal Mediterranean ecosystems (Burgess and Dawson 2004; Baguskas et al. 2016) and tropical montane cloud forests (Eller et al. 2013; Gotsch et al. 2014; Malhi et al. 2017), where fog (often leading to leaf wetting) serves as an alternative plant water source during the dry season. However, the effects of precipitation events are similar and foliar water uptake has now been described as affecting plant water and carbon relations in $>70$ species from a number of different ecosystems (Goldsmith et al. 2013).

The capacity for species to do foliar water uptake has frequently been established by means of water isotope labeling experiments (Burgess and Dawson 2004; Breshears et al. 2008; Limm et al. 2009; Eller et al. 2013, 2016; Berry and Smith 2014; Berry et al. 2014; Gotsch et al. 2014; Cassana et al. 2015; Emery 2016; Schwerbrock and Leuschner 2017). 
This method relies on exposing leaves to a water source that is highly enriched or depleted in heavy isotopes of oxygen or hydrogen compared to that of the xylem source water and measuring for the presence of this label in the leaf. The labeled water is delivered through a simulated fog or leaf wetting event using an ultrasonic fog machine or a simple spray bottle. A shift in the bulk leaf water isotope ratio toward that of the labeled water source is interpreted as foliar water uptake.

Water molecules can also exchange back and forth between the leaf and the atmosphere without a net increase in the mass of water in the leaf (Kim and Lee 2011). This occurs when atmospheric vapor pressure $\left(e_{\mathrm{a}}\right)$ increases relative to leaf vapor pressure $\left(e_{i}\right)$. As a result, the air-to-leaf vapor pressure deficit decreases and reduces the driving gradient for water loss from the leaf. Stomata generally open in response to decreasing VPD (Lange et al. 1971), leading to an increase in leaf stomatal conductance $\left(g_{\mathrm{s}}\right)$ in the light, even though net transpiration $(E)$ is decreasing to zero. Thus, with the stomata open, but transpiration suppressed due to $e_{\mathrm{a}} / e_{i}$ reaching unity (i.e., $100 \%$ relative humidity), water molecules simply move from the leaf to the atmosphere and vice versa with no net flux. This is akin to isotopic exchange between two pools of water in a closed system (Clark and Fritz 1997). Notably, this changes the isotope ratio of the leaf water, but does not lead to a net increase in the amount of water in the leaf. Thus, it is not possible to distinguish between a change in the leaf water isotope ratio due to foliar water uptake (net gain $\mathrm{H}_{2} \mathrm{O}$ ) versus a change caused solely by water isotopes simply exchanging back and forth (no net change $\mathrm{H}_{2} \mathrm{O}$ ) between the leaf and the atmosphere (Fig. 1).

The effect of the isotope exchange of water across the leaf surface on leaf water isotope ratios at steady state is described by the Craig-Gordon Model (Craig and Gordon 1965; Dongmann et al. 1974):

$\Delta_{e}=\varepsilon^{+}+\varepsilon_{k}+\left(\Delta_{v}-\varepsilon_{k}\right) \frac{e_{\mathrm{a}}}{e_{i}}$

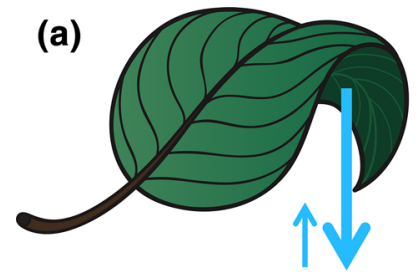

Transpiration $\left(e_{a} / e_{i}<1\right)$ Net loss $\mathrm{H}_{2} \mathrm{O}$ $\mathrm{H}_{2} \mathrm{O}$ isotopes enriched

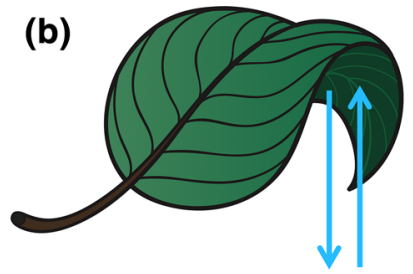

No transpiration $\left(e_{a} / e_{i}=1\right)$ No net change $\mathrm{H}_{2} \mathrm{O}$ $\mathrm{H}_{2} \mathrm{O}$ isotopes exchange

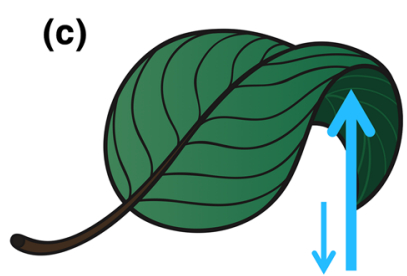

Foliar water uptake $\left(e_{a} / e_{i} \geq 1\right)$ Net gain $\mathrm{H}_{2} \mathrm{O}$

$\mathrm{H}_{2} \mathrm{O}$ isotopes taken up
Fig. 1 Leaf water isotope ratios can vary due to a the effects of transpiration when the ratio of ambient air vapor pressure to leaf intracellular vapor pressure $\left(e_{\mathrm{a}} / e_{i}\right)<1, \mathbf{b}$ the effects of transpiration suppression when $e_{\mathrm{a}} / e_{i}=1$, which results in no change in the mass of leaf water and $\mathbf{c}$ the effects of foliar water uptake when $e_{\mathrm{a}} / e_{i} \geq 1$, which
In Eq. 1, the enrichment in leaf water isotopes relative to the source $\left(\Delta_{e}\right)$ is a function of equilibrium $\left(\varepsilon^{+}\right)$and kinetic fractionation factors $\left(\varepsilon_{k}\right)$, the enrichment in atmospheric water vapor isotopes relative to source water isotopes $\left(\Delta_{v}\right)$, and the ratio of ambient air vapor pressure to leaf intracellular vapor pressure $\left(e_{\mathrm{a}} / e_{i}\right)$. Equilibrium fractionation occurs with the phase change of water from liquid to vapor within the stomata, whereas kinetic fractionation occurs with the diffusion of that vapor through the stomata and boundary layer into the atmosphere. Dongmann et al. (1974) notes that when $e_{\mathrm{a}} / e_{i}$ is at unity, the model simplifies to:

$\Delta_{e}=\varepsilon^{+}+\Delta_{v}$

In Eq. 2, the stable isotope ratio of water in leaves is not subject to kinetic fractionation and can be explained solely by a temperature-dependent equilibrium fractionation factor and the difference in atmospheric water vapor isotopes relative to source water isotopes. It is important to note that this theory cannot distinguish between the effects of foliar water uptake versus bidirectional exchange.

The exchange of water isotopes between leaves and the atmosphere in the absence of foliar water uptake can be demonstrated experimentally. We exposed leaves from well-watered poplar (Populus $\times$ canescens) plants growing in a high humidity ( $80 \%)$ growth chamber to a fog event using water with a depleted oxygen isotope ratio. We excised leaves at full water content, measured the leaf mass, and sealed the petioles from water entry. Leaves were either immediately exposed to fog or allowed to lose 5 or $10 \%$ of their initial mass prior to fog exposure to create a driving gradient for water to enter the leaf through foliar water uptake ( $n=1$ leaf each from 5 individuals per treatment). Fog was generated using an ultrasonic fog machine (Ultrasonic 3, CIS Products, France) and supplemented by periodic physical spraying for $1 \mathrm{~h}$ (i.e., fog leading to leaf wetting). We then quickly and carefully dried the leaf

results in a net increase in the mass of leaf water. The effects of bidirectional exchange of water isotopes between the leaf and the atmosphere observed in (b) cannot be distinguished from the net uptake of water isotopes from the atmosphere in (c) 
surfaces, re-measured the leaf mass, and sealed the leaf in a glass vial to later measure the oxygen isotope ratios of bulk leaf water via isotope ratio mass spectrometry. We compared the three treatments $(0,5$, and $10 \%$ mass loss) with the isotope ratio of the source water provided to the plants (for methods, see Online Resource). All data are available in the KNB data repository (Goldsmith et al. 2017).

The leaf water isotope ratios of all three treatments shifted toward the depleted isotopic label following fog exposure (Fig. 2). However, the leaf mass of the $0 \%$ treatment did not change, indicating the exchange of water isotopes even though there was no foliar water uptake. The 5 and $10 \%$ treatments recovered some (but not all) of their initial mass, as would be predicted by the establishment of a driving gradient for foliar water uptake. Due to the short duration of the experiment, the leaf water isotope ratios did not converge with the labeled water vapor, as would be
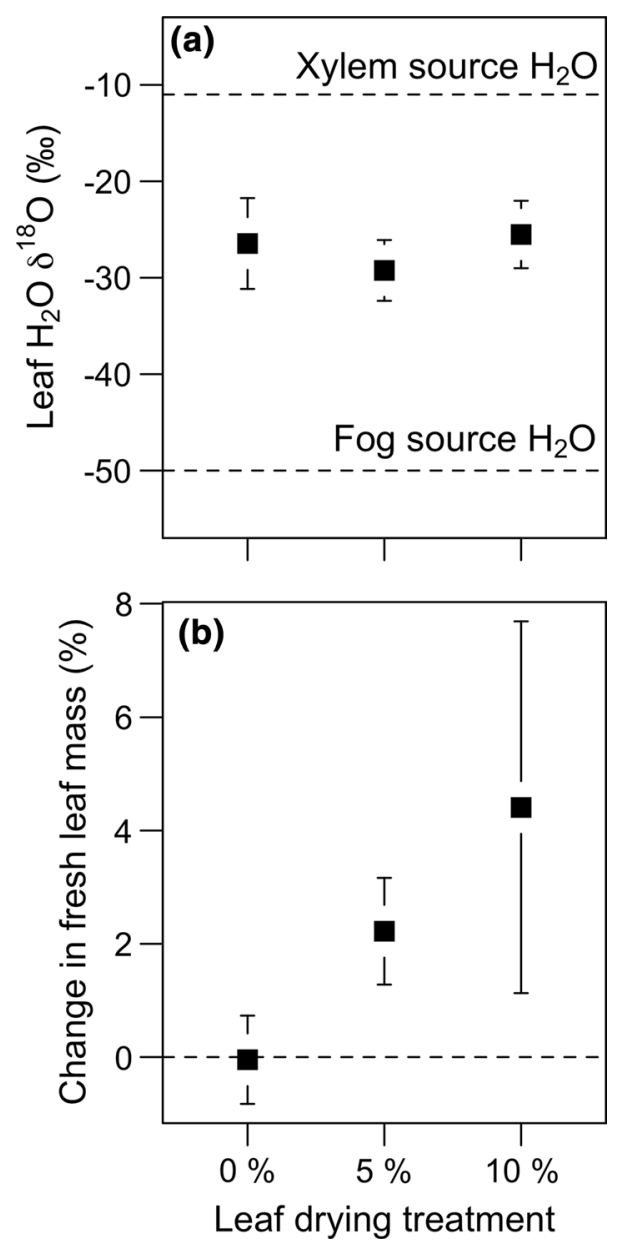

Fig. 2 Changes in a the $\delta^{18} \mathrm{O}$ of water and $\mathbf{b}$ the percent change in fresh leaf mass of poplar (Populus $\times$ canescens) leaves exposed to a fog source water depleted in $\delta^{18} \mathrm{O}$ after 0,5 , and $10 \%$ loss of fresh leaf mass achieved through bench drying $(n=1$ leaf each from 5 individuals per treatment). Data are means $\pm 1 \mathrm{SD}$ predicted by theory and has been observed in other experimental approaches (Kim and Lee 2011).

The observation that leaf water isotopes exchange even in the absence of a change in leaf mass is of particular importance if the primary pathway for foliar water uptake is stomata (Burkhardt et al. 2012). However, the pathways for foliar water uptake are not yet fully resolved. There is evidence for water entry through hydathodes, trichomes, fungal hyphae, and the cuticle, depending on the species under study (Burgess and Dawson 2004; Oliveira et al. 2014). However, even if the primary pathways were to be something other than the stomata, inferences regarding foliar water uptake could still be confounded by bidirectional exchange through open (or at night, partially open) stomata.

There are other analogous applications of water isotope tracers that should also be considered. Branch water uptake directly through bark has been studied by submerging branch segments into labeled water sources; even in the absence of stomata, it is likely that isotopic exchange will occur given sufficient time (Mayr et al. 2014; Earles et al. 2016). Several studies have also used differences between the stable isotope ratios of fog versus soil water to infer the proportional use of these two sources through sampling of xylem water isotope ratios (Berry et al. 2013; Fischer et al. 2016; Fu et al. 2016). Here, it must be assumed that the water in the xylem could come from a combination of the (1) soil water derived from precipitation, (2) drip of intercepted fog water from the plant canopy into the soil, (3) foliar uptake of fog water, or (4) bidirectional exchange of fog water with leaf water. The subsequent incorporation of these water isotopes into plant tissue (e.g., $\delta^{18} \mathrm{O}$ of tree rings) has also been proposed as a means of tracing the contribution of fog water to plant water use over time ( $\mathrm{Hu}$ and Riveros-Iregui 2016) and our results may help explain patterns observed in fog-affected environments (Anchukaitis et al. 2008; Zhu et al. 2012).

Foliar water uptake remains a real phenomenon. There are a number of different methods to independently establish its existence, including sapflow (Burgess and Dawson 2004), dye tracers (Eller et al. 2013), gravimetric approaches (Limm et al. 2009), and plant water potentials (Goldsmith et al. 2013). In fact, many of the research studies cited above combined stable isotope labeling experiments with other methods and thus the results are likely to stand. As no single method is perfect, we recommend that investigators try to use multiple means to establish foliar water uptake wherever possible.

Acknowledgements We thank L. Schmid for laboratory assistance and the reviewers for constructive comments. This research was funded through SNF (31003A_153428/1) and the European Community's Seventh Framework Program (FP7/2007-2013) under Grant agreement Number 290605 (COFUND: PSI-FELLOW). 
Author contributions statement GRG and RS conceived of the project. GRG, MML, and LC performed the research with assistance from MA. GRG analyzed the data and wrote the paper with contributions from all the authors.

\section{References}

Anchukaitis KJ, Evans MN, Wheelwright NT, Schrag DP (2008) Stable isotope chronology and climate signal calibration in neotropical montane cloud forest trees. J Geophys Res 113:1-17. doi:10.1029/ 2007JG000613

Baguskas SA, Still CJ, Fischer DT, D’Antonio CM, King JY (2016) Coastal fog during summer drought improves the water status of sapling trees more than adult trees in a California pine forest. Oecologia 18:1-12. doi:10.1007/s00442-016-3556-y

Berry ZC, Smith WK (2014) Experimental cloud immersion and foliar water uptake in saplings of Abies fraseri and Picea rubens. Trees. doi:10.1007/s00468-013-0934-5

Berry ZC, Hughes NM, Smith WK (2013) Cloud immersion: an important water source for spruce and fir saplings in the southern Appalachian Mountains. Oecologia 174:319-326. doi:10.1007/ s00442-013-2770-0

Berry ZC, White JC, Smith WK (2014) Foliar uptake, carbon fluxes and water status are affected by the timing of daily fog in saplings from a threatened cloud forest. Tree Physiol 34:459-470. doi:10.1093/ treephys/tpu032

Breshears D, McDowell N, Goddard K, Dayem K, Martens S, Meyer C, Brown K (2008) Foliar absorption of intercepted rainfall improves woody plant water status most during drought. Ecology 89:41-47. doi: $10.1890 / 07-0437.1$

Burgess S, Dawson T (2004) The contribution of fog to the water relations of Sequoia sempervirens (D. Don): foliar uptake and prevention of dehydration. Plant Cell Environ 27:1023-1034. doi:10.1111/j.1365-3040.2004.01207.x

Burkhardt J, Basi S, Pariyar S, Hunsche M (2012) Stomatal penetration by aqueous solutions - an update involving leaf surface particles. New Phytol 196:774-787. doi:10.1111/j.1469-8137.2012.04307.x

Cassana FF, Eller CB, Oliveira RS, Dillenburg LR (2015) Effects of soil water availability on foliar water uptake of Araucaria angustifolia. Plant Soil 399:147-157. doi:10.1007/s11104-015-2685-0

Clark ID, Fritz P (1997) Environmental isotopes in hydrogeology. CRC Press, Boca Raton

Craig H, Gordon LI (1965) Deuterium and oxygen 18 variations in the ocean and the marine atmosphere. In: Tongiorgi E (ed) Stable isotopes in oceanographic studies and paleotemperatures. Consiglio Nazionale Delle Richere, Pisa, pp 9-130

Dongmann G, Nürnberg HW, Förstel H, Wagener K (1974) On the enrichment of $\mathrm{H}_{2}^{18} \mathrm{O}$ in the leaves of transpiring plants. Radiat Environ Biophys 11:41-52

Earles JM, Sperling O, Silva LCR, McElrone AJ, Brodersen CR, North MP, Zwieniecki MA (2016) Bark water uptake promotes localized hydraulic recovery in coastal redwood crown. Plant Cell Environ 39:320-328. doi:10.1111/pce.12612

Eller CB, Lima AL, Oliveira RS (2013) Foliar uptake of fog water and transport belowground alleviates drought effects in the cloud forest tree species, Drimys brasiliensis (Winteraceae). New Phytol 199:151-162. doi:10.1111/nph.12248

Eller CB, Lima AL, Oliveira RS (2016) Cloud forest trees with higher foliar water uptake capacity and anisohydric behavior are more vulnerable to drought and climate change. New Phytol 211:489-501. doi:10.1111/nph.13952

Emery NC (2016) Foliar uptake of fog in coastal California shrub species. Oecologia 182:731-742. doi:10.1007/s00442-016-3712-4
Fischer DT, Still CJ, Ebert CM, Baguskas SA (2016) Fog drip maintains dry season ecological function in a California coastal pine forest. Ecosphere. doi:10.1002/ecs2.1364

Fu PL, Liu WJ, Fan ZX, Cao KF (2016) Is fog an important water source for woody plants in an Asian tropical karst forest during the dry season? Ecohydrology 9:964-972. doi:10.1002/eco.1694

Goldsmith GR (2013) Changing directions: the atmosphere-plant-soil continuum. New Phytol 199:4-6. doi:10.1111/nph.12332

Goldsmith GR, Matzke NJ, Dawson TE (2013) The incidence and implications of clouds for cloud forest plant water relations. Ecol Lett 16:307-314. doi:10.1111/ele.12039

Goldsmith GR, Lehmann MM, Cernusak LA, Arend M, Siegwolf RTW (2017) Data from: Goldsmith et al-inferring foliar water uptake using stable isotopes of water. Knowl Netw Biocomplex. doi:10.5063/F1GH9FXV

Gotsch SG, Asbjornsen H, Holwerda F, Goldsmith GR, Weintraub AE, Dawson TE (2014) Foggy days and dry nights determine crownlevel water balance in a seasonal tropical montane cloud forest. Plant Cell Environ 37:261-272. doi:10.1111/pce.12151

Hu J, Riveros-Iregui DA (2016) Life in the clouds: are tropical montane cloud forests responding to changes in climate? Oecologia 180:1061-1073. doi:10.1007/s00442-015-3533-x

Kim K, Lee X (2011) Transition of stable isotope ratios of leaf water under simulated dew formation. Plant Cell Environ 34:1790-1801. doi:10.1111/j.1365-3040.2011.02375.x

Lange OL, Lösch R, Schulze ED, Kappen L (1971) Responses of stomata to changes in humidity. Planta 100:76-86. doi:10.1007/ BF00386887

Limm EB, Simonin KA, Bothman AG, Dawson TE (2009) Foliar water uptake: a common water acquisition strategy for plants of the redwood forest. Oecologia 161:449-459. doi:10.1007/ s00442-009-1400-3

Malhi Y, Girardin CAJ, Goldsmith GR, Doughty CE, Salinas N, Metcalfe DB, Huaraca Huasco W, Silva-Espejo JE, Aguilla Pasquell J, Farfan-Amezquita F, Aragão LEOC, Guerrieri R, Yoko Ishida F, Bahar NHA, Farfan-Rios W, Phillips OL, Meir P, Silman M (2017) The variation of productivity and its allocation along a tropical elevation gradient: a whole carbon budget perspective. New Phytol 214:1019-1032. doi:10.1111/nph.14189

Mayr S, Schmid P, Laur J, Rosner S, Charra-Vaskou K, Dämon B, Hacke UG (2014) Uptake of water via branches helps timberline conifers refill embolized xylem in late winter. Plant Physiol 164:1731-1740. doi:10.1104/pp.114.236646

Oliveira RS, Eller CB, Bittencourt P (2014) The hydroclimatic and ecophysiological basis of cloud forest distributions under current and projected climates. Ann Bot 119:909-920. doi:10.1093/aob/ mcu060

Schwerbrock R, Leuschner C (2017) Foliar water uptake, a widespread phenomenon in temperate woodland ferns? Plant Ecol. doi:10.1007/s11258-017-0711-4

Simonin KA, Santiago LS, Dawson TE (2009) Fog interception by Sequoia sempervirens (D. Don) crowns decouples physiology from soil water deficit. Plant Cell Environ 32:882-892. doi:10.1111/j.1365-3040.2009.01967.x

Vesala T, Sevanto S, Grönholm T, Salmon Y, Nikinmaa E, Hari P, Hölttä T (2017) Effect of leaf water potential on internal humidity and $\mathrm{CO}_{2}$ dissolution: reverse transpiration and improved water use efficiency under negative pressure. Front Plant Sci 8:1399-1410. doi:10.3389/fpls.2017.00054

Zhu M, Stott L, Buckley B, Yoshimura K (2012) 20th century seasonal moisture balance in Southeast Asian montane forests from tree cellulose $\delta^{18} \mathrm{O}$. Clim Change 115:505-517. doi:10.1007/ s10584-012-0439-Z 